\title{
Towards Reconciliation in the
}

M otherland: Race, Class, N ationality,

Gender, and the Complexities of

A merican Student Presence at the

U niversity of G hana, Legon

\section{Jennifer Landau}

\author{
David Chioni Moore \\ $M$ acalester College, St. Paul, M N
}

\section{Introduction}

Study abroad has long been an important part of global education, and one distinctive chapter in its history has been the presence, notably since W orld W ar II, of U.S.-based (or "A merican") study abroad programs, particularly in western Europe. A certain set of assumptions grew up around these programs, including the greater antiquity and cultural prestige of the study destination; a general "racial" sameness between the (white) U.S. study abroad participants and their European hosts; a historical and cultural divide such that there was only rarely direct familial or affective connection between the student and the study destination; ${ }^{1}$ a relative homogeneity among the U.S. students; a roughly equal economic status of the sending and receiving nations; a destination culture historically not heavily affected by a wholly foreign U.S. culture; and finally a destination culture relatively unaffected by the American student presence.

Over the past fifteen years the worldwide growth of U.S. study abroad locations, the increasing number of "heritage" destinations, and an increasing theoretical sophistication have troubled these general assumptions. The following paper, co-written by an A merican alumna of a U S.- 
based study abroad program at the University of Ghana, Legon, and a U.S.-based American professor specializing in International and Black Atlantic Studies, will explore one particularly freighted instance of the end of such assumptions, by addressing the A merican student presence at the U niversity of G hana, Legon. Examination of the Legon case will, we hope, be valuable for all study abroad professionals, because the A merican student presence at Legon challenges all of the traditional assumptions noted just above. As with American student presence in nearly the whole post-colonial and post-Soviet worlds, American students at Legon are much richer than their hosts. Legon is also distinctive for attracting a high percentage of African American students, broadening the usual European/A merican U.S. study abroad demographic. Consequently the relationships between black and white A mericans, and those of both with their $\mathrm{G}$ hanaian hosts, have complex dynamics. H ere professionals may see parallels with U.S. heritage study el sewhere in the world. In addition, Ghana and the U.S. are hardly separate spaces: they bear the burden of three hundred years of overlapping history.

G hana was a major center of the centuries-long Atlantic slave trade which changed America forever, and millions of Americans have at least partial, and almost always unspecifiable, Ghanaian ancestry. Consequently, in recent times Ghana has been prominent in AfricanA merican efforts to rebuild trans-Atlantic links. Ghana has hosted African American figures including Langston $\mathrm{H}$ ughes, Richard Wright, James Baldwin, Maya Angelou (who lived there from 1961 to 1966), Malcolm X, Pauli Murray (who taught at the University of Ghana and authored the first English-language textbook on law in Africa), Louis Armstrong (who drew 100,000 at a concert in Accra in 1956), and most prominently W.E.B. DuBois, who died a citizen of $G$ hana, and was buried there, at age 94 in 1963.2 Prominent Ghanaians in the U nited States have included both Ghana's independence leader and first president Kwame N krumah, and current U.N. Secretary-General K ofi A nnan. Both were study abroad participants: N krumah was Lincoln University class of 1939, and Annan is Macal ester College class of 1961. H arvard's prominent philosopher $\mathrm{K}$ wame Anthony A ppiah is al so a G hanaian. The popularity of Ghana-originated Kente cloth is well-known in current American fashion, particularly among African Americans, and most recently as worn by $\mathrm{Bill}$ and $\mathrm{H}$ illary Clinton at a massive public reception 
in A ccra in March of 1998. W hen all this is combined with the enormous contemporary influence, in Ghana, of A merican and specifically African American culture, it becomes clear that one cannot culturally divide the U nited States and Ghana.

In consequence, the complexities of U.S. student presence at Legon are many. They range from the housing of U.S. students in well-appointed "international" floors to misunderstandings surrounding the word "Oburoni," the Ghanaian term for "foreigner" or "white." Despite the high expectations A merican students have for their time in G hana, and despite the great potential for cross-cultural learning on the part of both U.S. and G hanaian students, such expectations are generally under-met. And yet we believe that study abroad at Legon is an invaluable and, for some, even a life-changing experience despite, and in some ways because of the challenges we describe. Therefore, in this paper we hope to identify the chal lenges of this study abroad setting, to describe how they enrich and frustrate all participants, and to identify possibilities for improvement. Importantly, though racial matters will loom large in our paper, it is not, finally, our intention to answer all racial questions, nor do we feel able to fully represent all of Legon's "racial" complications. Therefore, this paper specifies no sure-fire recipe for what we are calling "reconciliation." Rather, by means of the multi-sourced light we hope to shed on Legon's complex social and identity relations, we aim to work towards the reconciliation of which we speak. We hope to spark conversation not only among study abroad providers and participants at Legon, but also among the larger study abroad community, particularly with respect to inequitable exchanges between students and host nationals.

W e will tackle the subject matter as follows. First, we will describe our research methodology, and then the diverse student groups. Then, we will assess misunderstandings between Ghanaians and Americans. Finally, we will link Legon's concerns to those of cross-cultural and global education in general.

\section{Methodology}

The core research for this study was performed by J ennifer Landau in the fall of 1998 while a student at Legon. Following a draft by Landau, this article was co-written by Landau and David Chioni Moore. The 
research was based on lengthy formal tape-recorded interviews supplemented by informal conversations and personal experience. Landau formally interviewed ten American students (evenly divided by race and gender), five Ghanaian students (both male and female), one program director, and two Legon faculty members, and conversed informally with dozens more from all of the above categories. Of course, no interview situation is neutral, and these interviews were, in particular, conducted by a white American woman, focused on charged topics, and necessarily covered only a small portion of the overall Legon population.

To partly compensate for bias- and acknowledging that there is no such thing as an entirely unbiased situation-Jennifer Landau received assistance from a final-year Ghanaian archaeology student, Yussif Abdallah. Abdallah conducted formal interviews with fellow Ghanaians - four male students, two female students, two departmental secretaries, two cleaners and one porter- and accompanied these interviews with a questionnaire. $\mathrm{H}$ owever, the reader should note that though equal numbers of Ghanaians and Americans were formally interviewed, these interviews comprise a good portion of the A merican student body but only a tiny, perhaps unrepresentative fraction of the G hanai an student population. Indeed, the Ghanaian students interviewed, and those on whose attitudes our A merican interviewees will comment, represent that portion of Legon students who seek involvement with foreign (and particularly W estern) students. As K wame Dougan, in 1998 a teaching assistant in the Department of Philosophy at Legon, commented on a draft version of this essay, "The vast majority of Ghanaian students on campus are conscious of foreign students only in the sense that they see them on campus; they are neither concerned about their problems and privileges, nor are they interested in their stay." Thus, though we are writing about relations among Americans and Ghanaians, this paper is principally about A mericans abroad.

Finally, the following analysis offers substantial excerpts from the interviews themsel ves, to allow direct engagement with the material. We have identified the informants as, for example, WAF1 (for white American female), GMS3 (for Ghanaian male student), and so forth: W and $B$ designate A merican whites and blacks, $G$ designates $G$ hanaians, $M$ and $F$ male and female, and numbers differentiate within each group. The themes which emerged from these inputs have generated our analysis. 
W hile, once again, no study can be free of bias, the range of perspectives incorporated are robust.

\section{B A C K G R O U N D}

The Institution of Study Abroad at the University of Ghana, Legon

The direct-enrollment program at Legon is comprised of six major programs: the Council on International Educational Exchange (CIEE), the North Carolina State University International Student Exchange Program (ISEP), Tufts U niversity, the State U niversity of $\mathrm{N}$ ew York at Brockport University of G hana Program, the University of M issouri, and the University of California Education Abroad Program (EAP- which bridges all nine of the major UC campuses and is housed at Santa Barbara). Following are the race and gender statistics on each program for fall 1998:

- Council (7 males, 30 females; 9 African Americans, 28 white A mericans)

- N orth Carolina State University (ISEP) (3 males, 8 females; 1 A frican A merican, 10 white A mericans)

- Tufts University (2 males, 7 females; 7 African or Caribbean A merican, 2 white Americans)

- SUNY Brockport (3 males, 11 females; 7 African or Caribbean A merican, 7 white Americans)

- U niversity of M issouri (2 males, 9 females; 5 A frican Americans, 6 white A mericans)

- University of California (8 males, 15 females; 6 African A merican, 17 white Americans).

Overall, women outnumbered men 80 to 25 , and whites outnumbered blacks 69 to 36. Foreign students reside in each hall on campus, though are generally in specially designated sections.

Foreign students are a major source of income for the $U$ niversity of G hana, paying approximately $\$ 2,000$ per semester in tuition and housing fees, in contrast to Ghanaian students, whose tuition is covered by the 
government in exchange for a year of national service. ${ }^{3}$ However, Ghanaian students are responsible for a "user fee" of approximately $\$ 70$, which covers housing and other academic facilities. This user fee - in the face of G hana's overall cost of living, per-capita income, and lack of institutional financial aid- is still, for many students, a struggle to maintain. Financially then, it is clearly in the U niversity of G hana's interest to enroll as many foreign students as possible. ${ }^{4}$ A U niversity vital statistics publication (University Planning Unit 1998) notes that the number of American students has been steadily increasing for a decade, climbing from 10 in 1991, to 56 by 1993, to the 1998 total of 105. U niversity officials indeed hope to fill as much as $10 \%$ of their enrollment with international students by 2002 . In line with this goal, the U niversity is constructing a new dormitory for foreign students, and thought has been given to creating a computer lab with Internet access specifically for them. The U niversity offers foreign students the school's best accommodations, new appliances, and increased leeway in dropping and adding classes. Indeed, as of December 2000, the Brockport and Cal ifornia programs had materials posted directly on- and not simply linked to- the Legon website. The lead paragraph on that website's home page (www.ug.edu.gh) notes, again as of December 2000, that "[d]ue to its excel lent reputation, the university has a history of attracting foreign students, particularly students from the U nited States." As will be detailed below, however, one result of Legon's strong welcome seems to be more the development of a separate system than a cross-cultural dynamic between the visitors - particularly Americans ${ }^{5}$ - and Ghanaians.

\section{Students at the University of Ghana}

In order to get a clearer sense of the cultural dynamics, we will briefly introduce the students

The A merican Student Body

Dennis Hickey and $\mathrm{K}$ enneth Wylie, in a fine book on the psychological relationship of Americans with Africa, ${ }^{6}$ note that "no traveler arrives at his destination with a blank slate. The cultural 'other' is al ways 
perceived through the medium of previous experience and personal acculturation. Our perceptions are greatly affected by our American experience" $(1993,8)$. As Hickey and Wylie note, this general American experience, particularly in the African encounter, is generally different for white and black Americans. O ur research at Legon confirms this observation. As a result, we will first look separately at black and white Americans at Legon.

M ost of the white A merican students interviewed expressed interest in learning about a culture very different from their own. Many noted that study abroad was the safest opportunity to encounter Africa, and a chance they might not get again. Some spoke of the experience as a personal adventure, something they expected to be both difficult and rewarding. One noted, "I was looking for a new challenge. Living in a different culture is challenging. W hen you live with different people you learn a lot about yourself" (WAM 1). This conception of the African experience as a challenge is not restricted to A mericans at Legon. A frica, though often seen as the "Dark Continent," has also been and continues to be romanticized by Americans as a place of escape or personal adventure. According to Hickey and Wylie, this more recent image was sparked in the 1960's by organizations like the Peace Corps, who introduced "the novel idea that Africa was the perfect place for wandering A mericans to work out their personal sense of mission" (180). Such conventions (which in fact go back as far as J oseph Conrad) are evident in many white A mericans at Legon. N onethel ess, most of them also seem aware of and frustrated by these conventions, and particularly by their promulgation in the $U$ nited States. O ne expressed that she al ways thought of A frica as the "mysterious continent, because we never studied it in school" (WAF1); such mysteries in fact have inspired many Americans to study at Legon.

Despite such myth-breaking desires, many A merican students also come to $\mathrm{G}$ hana expecting a traditional or "untouched" place. And indeed, often represented by its music, dance, batik, woodcarvings, kente and adinkra symbols, Ghana has been lauded for its exceptional maintenance of tradition. The 1998 School for International Training brochure, for example, promises that "with both traditional and modern art, music and dance flourishing throughout this country, Ghana is an ideal place to study A frican arts and culture." These motivations can easily be seen in the "art and culture" classes preferred by many Legon A mericans over the 
wide array of more academic offerings, such as in the social sciences. The stereotypical tendency is for white American men to flock to drumming and women to dance. In fact, Ghanaian students often follow the common inquiry "what course are you taking?" with a presumptive "music, drama, or dance?" The goal of learning about Ghanaian arts and having a "cultural experience" al so impacts how white A mericans choose to spend their time, and the kinds of friendships, often successful, they seek with Ghanaians.

The African American experience at Legon shares numerous contours with that of white A mericans, but also sharply differs, particularly insofar as studying abroad in Ghana is, for many, in part a quest for personal history or roots. As such their needs are not as tangibly satisfied as many white Americans' quest for culture. In the words of one African American:

I'vealways madetheconnection to A frica becausel know that my roots go there... I know that I'm a product of slavery, which can really be assumed. I don't really know but it's an educated guess, and most slaves came out of West A frica ... so going to W est A frica was just the right move, it was all there in terms of history itself (BAM 1).

Another framed his quest in artistic terms:

Some of the ideas that were coming up in my artwork, I wanted to see wherel was getting them from. A rtwork comes from a collective conscious - something you've done has been done before So I've al ways wondered, where do I go to see these things that have been done ahead of me and I'm just now doing. So I started looking at different art and found a lot of art from A frica with somethings that I was doing, and I had no idea. It was like opening a door and seeing everything fall out (BAM 2).

Significantly, many expressed a desire to be wel comed home: I didn't really know what to expect... I was just hoping for the best, that it would be cool. I was hoping to get more of a w elcome home type of vibe In terms of like, $\mathrm{Oh}$, black A merican, welcome home, this is your home, but I didn't get any of that. I've gotten a lot of welcome but I expected it to belike I was coming back to A frica, like roots, this 
is where it all began. I haven't gotten that reception (B A M 1).

Of course, the desire to trace one's roots is a quintessentially A merican phenomenon. Though the enormous interest in African ancestry sparked particularly by A lex H aley's 1976 book R oots was signal to the black A merican experience, the massive popularity of $\mathrm{H}$ al ey's R oots also among white audiences testifies to the general desire of all Americans (except, notably, $\mathrm{N}$ ative A mericans) to discover long-lost ancestry across the waters. ${ }^{7}$ Importantly, the A frican A merican quest for roots is compromised by slavery's historical abyss, and more recently by the mainstream (mis-)information available about Africa in the U nited States. These forces are apparent in the disapproval shown by family and friends of students studying abroad in Africa. W hile many African A mericans who come to $G$ hana have high expectations, some noted that their parents were not supportive:

I said I'm going to $G$ hana, and the only thing they said was, "W hy are you going to $A$ frica?" They are not curious about it, they don't associate with A frica, and it's not anything that any of them would decide to do. It wasn't a positivething. It was something I was going to have to do on my own (BA F 2).

Yet many Americans who go to $\mathrm{G}$ hana look to examples set by figures such as M alcolm X and W.E.B. D uBois when, with the advent of the A frican independences and the growth of U.S. civil rights, they turned to Africa both for a metaphoric and physical home. ${ }^{8}$ These leaders not only continue to serve as role models in the U nited States, but al so inspire current African Americans to come to A frica. As one informant explained,

So going to A frica was just the right move It was all there in terms of history itself ... in a dass called B lack Power and the Civil Rights $M$ ovement we learned about how some people, $M$ alcol $\mathrm{m} X$ and others worked for SN CC and how they went to A frica and I thought that it was amazing. Some students were sent to $A$ frica, and $M$ alcol $m X$ on his pil grimage came to $A$ frica too and stopped in $G$ hana. I've read so many books on $\mathrm{M}$ alcol $\mathrm{m}$ and the $\mathrm{P}$ an-A frican movement. A Black man going to $A$ frica, you just have to see it for yourself, just something you have to see, just in terms of Black people, B lack presidents, and B lack people in all sorts of power. Black people as the majority, you 
are no longer the minority. It's amazing, and I wanted to witness it for myself (BAM 1).

The poet Maya Angelou, who came to Ghana at the dawn of its independence, expressed similar sentiments forty years before. "Seeing Africans enter and leave the formal building made me tremble with an awe I had never known. Their authority on the marble steps again proved that whites had been wrong all along. Black and brown skin did not herald debasement" (Angelou 16). Thus beginning roughly in the 1960s, and continuing to this day, Africa has undergirded much in African A merican self-conception. This contrasts sharply with what James Baldwin noted about his own 1930s upbringing:

At the time I was growing up, N egroes in this country were being
taught to be ashamed of A frica. They weretaught it bluntly by being
told that A frica had never contributed anything to civilization, or one
was taught the samel esson more obliquely and even mor effectively, by
watching nearly naked, dancing, comic-opera cannibalistic savages in
movies $(1961,6)$.

The distance between the 1930s and today can be measured in part by the nomenclature shift from "N egro" to "Black" to "African A merican," and in part by more mundane signals, such as art purchases by some of Legon's A frican A merican students, who comment, for example, that "I want to decorate my home, I want my house to be decorated with African art just because I want that to be in my household for my children, for myself" (BAM 1). Or, in the words of another: "In school I didn't receive any education about A frica, but in my house I did, as a young person I did. My parents al ways tried to keep us informed about where we came from and where we were going. So A frican studies was in my household" (BAM2). Thus, overall, this post-1960s, post-R oots push towards Africa in A frican American communities partly accounts for the high expectations of African Americans at Legon. In sum, speaking broadly, and allowing for individual variation, we find two sets of motivations for Americans going to Legon: a somewhat achievable, and often general and diffuse, arts-and-culture desire on the part of whites; and a much more conscious and emotion-laden, and less easily achievable quest for blacks. 
Yet with these differences in mind, many black and white expectations are not racially divided, but instead derive from a common American experience. One American reported that his school's international center characterized Ghana as a place of "development and unstable government, dangerous to go to," and suggested the possibility that "school would shut down and we'd have to come home or some type of revolt would break out" (BAM 2). Other common expectations included "more jungle area, more animals everywhere" (WAM 2), or "more village areas and fewer structures, fewer concrete structures, fewer cars and all that kind of stuff, no paved roads" (BAM 2). Yet another noted that he was "surprised about how beautiful and well-groomed the campus of Legon was kept" (WAM 1). Clearly many of these responses are derived from negative A merican images of Africa. One student expressed her discontent:

A frica is still the "D ark Continent" in the States. Y ou have to know it is one of the seven continents and that's pretty much all. A nd of course what you see on television. What you see are starving people, elaborate ceremonies with people in costumes, and war and political turmoil, and that's it. You don't see anything like A ccra, where you just havea city where peopl earegoing about their business, doing their jobs ... It's al ways problems that come up (B A F 1).

One result of this media image is concern- on subjects from political turmoil to tropical disease - on the part of many parents. Their fears of Africa, which exist side-by-side with its pristine and peaceful "noble" image, exist in both white and African American families:

M y dad dipped this $N$ ew York Times series on A ID S in A frica which ran all summer long ... M y next door neighbor was arying, really, really arying for my safety, for me, for everything, she was really upset for me (WAF 2).

They wereafraid when they heard there was a bombing in A frica. I was like that is East A frica; I'm going to W est A frica. I mean they trusted my judgment, it was more of a question of, there are problems over there and I was like $Y$ es, but nowhere near where I will be (BAF 1). 
Or finally:

It took a lot of convincing to get my parents to le me come. M y parents were just like, there's disease there ... we have air conditioning, electricity and running water. Why would you ever want to go anywhere e se? I was really discouraged. Then my unde, who has done a lot of world traveling, talked to my father. H esaid a program sponsored by his $\mathrm{U}$ niversity in the States is the safest opportunity your son is ever going to have to go to A frica (W A M 2).

Although students may be aware of media biases, images of Africa inevitably affect relationships between Americans and their hosts. This framework, combined with economic privilege, defines the general American experience at Legon.

\section{The Ghanaian Student Body}

Though A merican students are the focus of this research, it is important to also know Ghanaian students at Legon. For the purposes of this article, we will focus on their status as Legon students. For Ghanaians, it is a privilege to attend the University of $\mathrm{G}$ hana. First, it is costly to continue beyond the secondary level, and while some students are financially secure, many others struggle. Some families marshal all available resources, since a U niversity degree is often regarded as a ticket to success. Furthermore, admission to Legon is highly competitive, which enhances Legon's prestige. As one informant said, "Y ou feel a sense of pride as a student at Legon. Somehow there is respect for you" (GMS1).

$M$ aintaining student status can be difficult. Even once one gains admission, one must contend with fees, housing shortages, and course selection. As one student put it:

A dmissions to this $U$ niversity among $G$ hanaians is very keen before you get here Even when you get admission, they don't give you the course that you want to take. M aybe you would opt for Sociology or Psychology or Social Work. Well, they'll give you a course like Swahili, Religions or A rabic. I want to do this, but when you get here you realize that your plans have changed (G M S1).

As a result of struggles to meet costs, gain campus accommodation, 
and make grades, the Legon academic environment is competitive and serious. This seriousness contrasts with the attitude of many U.S. students, who view their time abroad as a vacation, adventure, or personal exploration. While university degrees lead to better employment in both countries, due to wide disparities in national economic strength and educational infrastructure such degrees are common in the $U$ nited States but rare in Ghana, which, though strong by African standards, has just three major institutions of higher education. Thus, competition among Ghanaian students is fierce. W hat is more, many G hanaians express ambitions to continue school and work abroad. These ambitions, combined with great economic gaps, creates an often frustrating dynamic between $\mathrm{G}$ hanaians and A mericans, as will be detailed below.

\section{Major Themes of Misunderstanding}

At this point, we shift from general background to accounts of common misunderstandings. We will begin with the economic disparity between Americans and $G$ hanaians, then turn to conflicting expectations and dynamics (A frican American/G hanaian, W hite American/G hanaian, and Black A merican/W hite A merican), and conclude with more mundane forms of miscommunication.

\section{Economic D isparity}

The economic gap between Americans and Ghanaians is a major source of tension. As one white American expressed, "I think the hugest difference between the U.S. and G hana, sure people are black and it's hotter here, but it's all about money. Money is the main difference by far" (WAM 2). As noted above, Legon's foreign students pay a fee some thirty times greater than that of their Ghanaian peers. Within this foreign group, and for reasons discussed in footnotes above, A merican students are treasured commodities and are thus given preferential treatment. Many A mericans expressed discomfort with this treatment:

I think $\mathrm{G}$ hanaian students get pissed off at A mericans because of the special treatment- which we do, we do get special treatment. Like, an A merican student complained, and the water was turned on. If a 
$G$ hanaian student complained, there's no way (WAF3).

This privileged treatment is also on the minds of some Ghanaians. One commented:

I think A merican students are more privil eged then us $G$ hanaian students here $Y e s$, people have been complaining a lot. $\mathrm{N}$ ot just A mericans, other foreign students, N igerians, Gambians. B ecause this school is for $G$ hana- we have to get all the benefits we can. I t's because of the money the school collects; they try to cater the environment. I mean not even conducive environment, I mean too conducive, higher then what wethe $G$ hanaians are having. W e G hanaians are five to a room. Life on campus is to the advantage of foreigners and to the disadvantage of G hanaians (G M S1).

$\mathrm{H}$ aving sketched out these basic economics, we now turn to two specific manifestations of the differential: campus housing, and the economics of friendship.

\section{The Housing Dilemma: Segregation or Integration}

At present, most A merican students at Legon are housed in foreignstudent sections of each hall. A mericans generally room together, two to a room. Their $\mathrm{G}$ hanaian counterparts, in contrast, are in a housing crisis caused by inadequate campus accommodation for those admitted. H ence, many Ghanaians are assigned to live with up to six roommates in spaces built for two. "Perching" - the common but unsanctioned practice of living in a relative or friend's room without permission-al so contributes to the crunch. Consequently, much of the resentment towards foreign students apparently focuses on housing, since increased numbers of foreign students seem to reduce avai lability for nationals. In addition to this frustration, many Americans and Ghanaians expressed dissatisfaction with even broader social segregation. An American commented, "W e are pretty segregated. We're not getting the full experience. We are two to a room" (BAF1). Or, as she said at greater length:

There is no common space in the buil ding where you can run into peopleand talk. I think that theliving situation is the main reason that 
I haven't met G hanaian women. I expected to have a $G$ hanaian roommate, but I understand that there have been problems in the past. I think that part of the experience is being in $G$ hanaian sociey. It is too easy for me to come here and not be immersed because I'm on a foreign floor, so I seeforeigners. If you had a roommate, or at least neighbors, that are $G$ hanaian you learn so much more about the culture. $D$ efinitely more forced interactions (BA F 1).

Some G hanai an students shared this desire. One noted, "you people came to $\mathrm{G}$ hana not only for the academics but to learn about our culture. You didn't come to make friends with A mericans. So maybe every room should have one foreigner so that you learn ... So we are learning from each other" (GFS2). A Legon faculty member affiliated with a U.S. program also expressed dissatisfaction with the housing situation:

To be frank with you, it is not fair for foreign students to be two in a room and $G$ hanaian students to be six. They have a scholarship.

Their government provided them with the money to be here So this is something that has to be addressed if we want the $G$ hanaian students to be comfortableliving, working and interacting with for eign students.

Unfortunately, these conditions will not likely change soon. The government has recently increased the G hana-student user fees, and yet, since foreign students are a major source of income, the U niversity is investing in a new foreign student dormitory rather then improved housing for G hanaians. Such choices seem unlikely to improve relations.

\section{The Economics (and Gendered Economics) of Friendship}

The economic disparity between A mericans and Ghanaians complicates the formation of intercultural friendships, in part because, it seems (and this is of course true around the world), A merican students meet disproportionate numbers of people with "instrumental" or "ulterior" motives. In part this results from American students, past and present, who have chosen $\mathrm{G}$ hanai an friends seen as "not correct," or who have been perceived to be sexually promiscuous- a charge especially lodged against U.S. women. Regardless of historical or present causes, many A merican 
students are skeptical of friendship with $\mathrm{G}$ hanaians. They express frustration with the number of people who seek to befriend them merely because of their country of origin and assumed wealth. All of the A mericans interviewed expressed this sentiment to some degree. "W here are you from? I have a cousin in the U.S. It's al ways the same questions" (W AF2). Or, "It's hard to be friends with G hanaian students. The ones that you want to be friends with are not the ones who ask you where you are from ... The students that aren't so impressed with A merican students stay away" (WAM2).

Many American students also expressed frustration with the assumption that all Americans are rich, when American self-perception can be different: "I don't like that they think we have so much money. I have barely enough to be here. W hen we got here people were telling us all the expensive restaurants. Like we wouldn't want to eat at the Bush Canteen" (W AF 1). ${ }^{9}$ H owever not every A merican student seemed negatively affected by the economic situation. In fact one found his privilege invaluable for learning:

They'll ask really interesting questions, like, 'We hear in A merica when something breaks, peopl ejust throw it away.' Y ou haveto think about it for a second. But then it's like, Yeah, pretty much, when something is broken in the U.S. you throw it away, you don't fix it. So you learn a lot about your own country from their honesty (WAM 1).

Importantly, dissatisfaction with the effects of economic differentials is not restricted to A mericans. Yussif Abdallah, who separately interviewed $G$ hanaian students for this study, noted that many $G$ hanaians al so express concern with the economic undercurrent of relationships, and are scornful of their peers who make a habit of befriending Americans. Some assume that a Ghanaian who befriends an American is doing so for the money, or to earn a "one-way ticket" to the States. Ghanaian men who befriend A merican males are often label ed opportunists, and may be ostracized by classmates. H owever - and here a gender dynamic familiar in study abroad worldwide comes into play- G hanaian men who have relationships with American women are seen to add to their own status, in part for financial reasons. A white female student commented: 
W e went to this dub and this guy was trying to stake a claim on me. I fat like hewas sticking a polewith a flag on mebecause what white women represent, what white A merican culture represents is money (WAF 3). 10

It should be noted, though, that most of the "opportunist" men (and some women) are not students, but locals lured by the presence of Americans.

At the same time, and continuing in the vexed nexus of money and gender, all sources suggest that Ghanaian women who befriend white American men are seen as opportunists and possibly even prostitutes. This bias is common worldwide, where men who associate with many women are hailed, while women who associate with many men are condemned. The Ghanaian dynamic results partly from the colonial encounter, during which white men took Ghanaian women as concubines or prostitutes, an image seemingly present even in modern-day views of Ghanaian women with "Oburoni." Some suggest that it would be more acceptable for a G hanaian woman to date an A frican A merican, although it would still be assumed that she sought financial security. Overall, it is much more common for $\mathrm{G}$ hanai an men to befriend A merican women than for $G$ hanaian women to befriend American men. And many A merican women and men noted that it was much harder to forge friendships with G hanaian women than $\mathrm{G}$ hanaian men.

In sum, American students are undeniably economically advantaged, and this advantage influences all student relationships and perceptions. A mericans are physically set apart from their Ghanaian peers, and their spending power makes them a target for opportunists both on and often off the campus. All this makes many Americans wary of their $G$ hanaian peers, deserving or not, and makes $G$ hanaians very conscious of U.S. student wealth. In the end, economic disparity and the segregation it breeds impedes fruitful cross-cultural exchange.

\section{Cultural Gaps}

H ere we move beyond the consequences of the real and imagined economic gaps among Legon students, and turn to other, more "cultural" dynamics which characterize study abroad at Legon. First, we will discuss 
the general ly unmet A merican expectation that A frica will be un-W estern and pristine, and then turn to two complex areas in Ghanaian/A fricanAmerican relations: the reception $A$ frican American students receive versus that of white students, and the use of African A merican culture by Ghanaians. Then we will turn to the use of the term "Oburoni."

1. Disappointment in

W esternization/Expectation of Pristine

As noted above, American study abroad students are powerfully shaped by images at home. In the case of Africa, American media and schools offer sharply different images from what Ghana actually provides. $\mathrm{H}$ ickey and Wylie note that many Americans, on their first and typically urban experience of Africa, ask "W here is Africa in all this? W here are the quiet cone-shaped huts, the silent herdsmen, the women pounding at the mortar, the kitchen smoke wreathing the gol den thatch, the elders in council, the distant grove of ceremonies as old as time?" (1993, 114). Among Americans at Legon, many expressed similar disappointment in the pervasi veness of W estern artifacts, ideologies, and styles. O ne noted: "I did not expect any of the influences from Europe or like how everyone wears jeans and stuff like that. I never thought of that" (BAF1). Or another: "People wear things that I think are crazy to wear. I just will never understand why people wear such hot European clothing when it's so hot! W hy are you wearing jeans, a long sleeved shirt, dress shoes and socks to class?" (BAF2). Or a third who differentiated between the villages where the women have "short natural hai $r$ " as opposed to the Legon women students who "all either have braids or their hair straightened" (BAM 1). Or finally this:

It's a little disappointing because they have such a rich culture and they're not taking advantage of it. Like you look at the girls on campus, they are so W esternized. They are all wearing booty shirts and little tight skirts. A lot of them arewearing W estern styles. Someare still wearing $G$ hanaian styles, but there is definitely a push towards Western (WA F 3).

Some G hanai an students express similar di sappointment, as did this female student: 
W eG hanaians like the black col or, lines on the neck, beautiful heavy brown nice legs, plenty hips and breasts. B ut everybody is adopting the white way of thinking. People are conscious of their hips. $\mathrm{N}$ ow, everyonewants to go the slim way. Y ou should havea littlebit of hips but they want you to look more like the whites than the $G$ hanaians. On campus, you can wear your hipsters, your short skirts. We are not used to, because our body, weare not supposed to be exposing our thighs, hey, only for your husband. But when these girls go on vacation abroad, and bring back their voguedress, short A - line skirt, hipsters. You yourselves, you the whites are not even wearing such d othes. Y ou whites don't even likedresses... T here was this [ G hanaian] girl who wore a velvet dress when the sun was shining (G FS3).

In addition, both American and $\mathrm{G}$ hanaian students expressed irritation with Ghanaian adaptation of American accents or phrases. One A merican commented: "There are Ghanaian men that have never left G hana and they'll be talking to me in an American accent. And it's disappointing because you are like, what are you trying to emulate? W hat are you trying to be that you are not?" (WAF3). Or, said this Ghanaian:

Some $G$ hanaians fel that they are on top of the world because they have gone to stay abroad and they don't even speak real English anymore, they speak slang. Excuse me, I comefrom $G$ ermany. Welaugh ... some respect them. Those who dream of settling in the U .S., they want everyone to know ( $G$ FS3).

J ust the same, although some Ghanaians also express frustration with western styles and ideals on campus, many also express resentment towards A mericans who judge G hanaians by their level of A fricanness:

A nd of course it irritates them the way we are so un-A frican, or proW estern, and especially when they start trying to teach you how to be A frican, then you get irritated. L eft on my own, I would admit that yes, most people are ready and willing to throw away everything $G$ hanaian in favor of everything A merican. B ut on the other hand, it's an in-house thing, and you don't want someone e se coming from somewhere else to tell you there is something wrong (G F S1).

This negative response to A merican desires for "authenticity" is less 
surprising when one consi ders the advice at least some A mericans have for their G hanaian peers:

$N$ umber one, $G$ hanaians have to stop watching so much A merican television. They need to be happy with what they have here; they need to behappy with who they are, becausea lot of them, especially the ones you meet on campus want to be something that they are not. They want to be A merican, they want to go to A merica and I don't understand that (BAF3).

\section{The Reception of A mericans}

The relationships among African Americans, white Americans and Ghanaians is complex, and we cannot do full justice to it here. As we will see, an important dynamic in the way A frican Americans- who sense kinship with Ghanaians before arriving - feel they are received, has to do with the way white A mericans seem to be received. This in turn creates tension among the A mericans. Thus in this section we will focus on that multi-directional dynamic.

Overall, we believe that much of the misunderstanding at Legon stems from unmet expectations on all sides, which result from numerous overlapping historical factors. The most recent, and in ways most powerful of these factors are the often negative global media images of African Americans. As K wame Dougan comments:

W hile W estern media portrays A frican A mericans as lazy, violent drug addicts and criminals, it portrays A frica as impoverished, wartorn, disease stricken and uncivilized. This, combined with the ignorance and sometimes almost criminal indifference with which many $G$ hanaian students regard the slave trade, and the different milieu in which both sets of people have been accul turated, leads to misunderstandings between $\mathrm{G}$ hanaians and $\mathrm{A}$ frican $\mathrm{A}$ mericans which deny the latter the warm homecoming welcome they expect.

Consonant with this observation, many black Americans express disappointment in their reception. Indeed, nearly all informants believe that U.S. whites are better received than U.S. blacks. The following three comments capture this: 
I have a white friend, a A sian friend, and an A frican A merican friend that went to a wedding, and the A frican A merican student was basically ignored. I mean they would talk to her but they were catering to the white and $\mathrm{A}$ sian students. They werelike, what can we do for you, you've come all the way to $G$ hana. W hich is interesting because you think, if you're coming back to A frica, you'd be able to escape certain prejudices (WA F 3).

I think a lot of A frican A mericans have conflicts, because we feel that white people are treated better. I think it depends on the $G$ hanaian and their background. M ost of us expected to feed more at home here and to be more accepted then the whites. If you talk to A frican A mericans, they have very different opinions about $G$ hanaians then a white person would. They would say, 'oh, they are not as nice to me' (BAF1).

They need to stop catering to the whites. That was one thing that totally, totally threw me. That I could be in a village somewhereand trampled to death by people running up to the white folks or even on campus or even in Osu or wherever else. Where $G$ hanaians want to talk to whitepeople morethen they want to talk to black people. I have a real problem with that. I mean I could just go stay in the U nited States for free and have experiences like that (BA F 2), ${ }^{11}$

This sentiment has serious consequences for relationships between white and black A mericans on campus. Some A frican A mericans interviewed expressed resentment toward the white American presence on campus, and nearly all noted that white Americans are preferentially received. Furthermore, some informants observed that black and white American social styles played a role. This African American student explains:

I'm not the kind of person to throw my confidence into a person, espe cially if I'm meeting them for the first time or even after that. I don't giveaway my trust so easily and that's something that I've dealt with in the States and something that carries over now. We need to explain that to $G$ hanaians because they wonder why A frican A mericans behave so strangely or act so withdrawn. We have had to be wary of 
people I don't necessarily believe in being belligerent or rude but just not giving yourself away immediately. White A mericans have the ability to trust someone quickly. We both came over, but we are not from the same place (BAF3).

K wame D ougan suggests that this acculturated African American reserve can have unintended negative consequences, since the hesitancy of African Americans to engage in Ghanaian greetings can be perceived by Ghanaians as "anti-social, a display of a feeling of superiority." Though Dougan recognizes the differences in background, he suggests that many other $\mathrm{G}$ hanaian students, less familiar with these differences, "are angered by the habit of not-greeting among most African A mericans." Further complicating this situation, $G$ hanaian students often seem resentful of a perceived African American "claim" or "right" to be welcomed back, which is often set against a perception that white A merican students make greater efforts, socially and otherwise, to immerse themselves in G hana. As one Ghanaian commented,

Thereare a lot of people here, maybe we are not really educated about the slavery thing and a lot of $G$ hanaians don't careanyhow. OK, so maybe we should be accepting of A frican A mericans and be more understanding of their situation and understand that they are sort of in-betw en worlds. B ut it's easier to sympathize with somebody who is not that aggressive. M aybe people would sympathize but when you are coming here and daiming a welcome home as your right. It's like you are trying to displace the people here (G SF 1).

O ne Legon faculty member explained this misunderstanding:

In $G$ hana, the racial politics that goes on in the $U$ nited States is unknown, at least not to the same extent. P eopl esee each other as individuals rather than as divided because of color. M any black A mericans wonder why we get along so well with white people Well, why shouldn't I? Is there a reason that I should treat them different then any other person? Well, there is a reason, colonization and all that. B ut when arewe going to change? We are going to go on with that attitude and treat them like that when they have done nothing to deserve that kind of treatment? I would say that most $\mathrm{G}$ hanaians would behave the same way to a white and black $A$ merican. 
In this light, many $G$ hanaians expressed a desire to focus on the present, and frustration with African Americans who concentrate on the past. O ne commented that African A mericans are more concerned with slave castles than with contemporary Africans. M any $G$ hanaians were al so critical of the tendency of some African Americans to disassociate with white Americans. In response to these remarks one African A merican student commented:

Y ou can't understand if you have never felt racism. It doesn't sound like a big deal but it is a big deal. If you haven't seen it you can't possibly understand where I'm coming from. That's why black people stick togeher. [... ] It all stems back to slavery. To say that I'm too caught up in the past is bullshit (BAM 1).

There is, then, a way in which common American misperceptions about Africa and Ghana are matched by Ghanaian misperceptions about the U nited States, and particularly American racial history. Both sets of ignorances impede friendship between the groups. It is also clear that American students, both black and white, are forced to examine their domestic racial codes abroad. In fact, some whites noted that they were forced to deal with "race in America" for the first time in G hana. Thus "racial" issues at Legon are not merely binary, not merely threefold, but are rather woven in complicated patterns, as will be seen again, in our discussion of the term "Oburoni."

\section{G hanaian U se of A frican A merican Culture}

In ways distinct from- but in other ways related to - the complexities of A frican American reception at Legon is the popularity of A frican A merican culture among Ghanaians. The widespread appropriation of black A merican cul ture across the gl obe has been the subject of much controversy within the diasporic community at large. It calls into question the relationships among post-slave cultures of the Atlantic world and their commodification. ${ }^{12}$ Many African Americans interviewed were offended or at least frustrated by the pervasive campus use of black A merican slang and to a lesser extent, black American culture, including recorded music, the "R\&B" style of dress, the idolization of A frican American sports and music figures, and the "bad" image of the A merican black. 
I mean I get the usual questions: D o you rap? Is Tupac alive? You walk likea black A merican. H ow's that? Then they show you. A nd then somei mes they use the ebonics slang. It's kind of amusing because it is in a sense black culture it's M ichad Jordan, sports, and it's Tupac. Y eah, how they look up to those idols more than anything else and they see a black A merican and they're like, "OK, W hat's your favorite basketball team? M ichael J ordan, Is M ichael J ordan your favorite player?" M ichael J ordan this, M ichael J ordan. Tupacis the best. B ig Puff D addy. It's not looked down upon; they're just like, yes (BAM 1).

$M$ any other interviewees expressed similar frustrations with the pervasiveness of U.S. black cultural references in conversation. Many students feared that these references skewed Ghanaian views of African Americans: "I asked some guy what people here thought about black A mericans. He said, you have to understand that we are extremely influenced by American culture. Some people might think that black A mericans are bad and violent, but that just depends on the person's education" (BAM 1). A nother African A merican commented, "I think when I'm greeted it's often to establish peace between us as opposed to just greeting me as a person, to make sure that I am not a violent person" (BAF3).

The use of U.S. black vernacular, which is highly politicized even in the U nited States, and its decontextual ized usage by Ghanai ans, seems to be the greatest source of A frican A merican unsettlement. One explains at length:

I get really offended. I've been called "nigger"... "H ey, what's up nigger," the wholeblack A merican thing coming over. I froze; I waslike, what?! I'm back in the States. W hat?! Wait. W hat are you saying? I was more disappointed than anything else because that word for me, it's just somehing that I can't even say. I know it's a slang term and means brother in the context. B ut I just can't say it and I don't like to be called it. I don't like it and to have A fricans saying it to me, "H ey, nigger." It's just like the whole thing coming over (BAM 1).

Clearly, black A merican culture, historically deval ued but now glob- 
ally famous and widely commodified, is laden with controversy. Its use by Ghanaians can be interpreted by African Americans in a twofold way. When a Ghanaian, for example, greets an African American with "W hassup?," in a way he both affirms his interlocutor's A merican identity and establishes a boundary between the two.

Of course Ghanaian infatuation with African American culture should not be exaggerated. W hile questions about Tupac and Michael J ordan may indicate some Americanization, it is arguable that Tupac, Michael Jordan and even Monica Lewinsky are little more than foreign moral fables, well (but not overly) incorporated into Ghanaian culture. As K wame Dougan notes, Ghanaian musical stars like "Daddy Lumba, Amakye Dede or K ojo Antwi still draw more people to the dance floor than Puff D addy, or any other W esterner for that matter." We should al so note that U.S. vernacular usage does not always come from Legon students. Many campus entrepreneurs, traders, school children and other denizens generate a good portion of the comments. Furthermore, it is reasonable for Ghanaians to share their knowledge of A frican A merican culture with someone they think comes from that culture, just as white A mericans might say "bonjour" to visitors from France. Our own interest is not in "authentic" African American use, but rather in the perceptions of these comments.

\section{The Term "Oburoni"}

Our last item in this catal ogue of cultural vexations- that is, issues that arguably impede cross-cultural learning between A mericans and G hanaians at Legon - is centered in a single word. Language, and especially the language of group names, is charged around the world. W ho counts as "coloured" or "African" in South Africa, full- or half-caste in South A sia, or Ainu or K orean in J apan can have enormous local consequences unseen by visiting observers. In the $U$ nited States, most of these troubles surround the names for "race." As a result, Americans will be especially sensitive to "racial" classifications made of them abroad, even if in the local context those classifications are light on judgment. In G hana, specifically, the term "O buroni" is used in varying ways- at times generically for foreigners, and at other times specifically for whites. ${ }^{13}$ Though the term comes from Akan, spoken by about 44 percent of Ghanaians as 
a first language, and although every language has its own term for foreigner, "Oburoni" is widely understood in G hana and is commonly used as a greeting and label. "O buroni" has historical and social connotations which go beyond its common translation as "foreigner" or "W hite," and even beyond its literal translation as "someone from 'aburokyire,' the land beyond the horizon" - the explanation provided in Dolphyne (1996).

$K$ wame D ougan notes that the term Oburoni derives from the root word 'abro,' which translates as 'mean, selfish or destructive,' and the affixes ' 0 ' and ' $n i$ ' which designate the singular for person. Thus literally it can be translated as "a bad, mean, selfish or destructive person." The term was historically ascribed to Europeans for evident reasons. Over time, however, the term has lost much of its derogatory meaning and now refers to any white, or indeed any foreigner who behaves like whites. In fact changing perceptions of Europeans has given the term some positive connotations, such as western-educated or rich. It is not uncommon for a Ghanaian university student who has never left the country to be called "O buroni" by his family upon returning home for vacation.

In common usage "O buroni" carries neither high honor nor strong insult. It is commonly used in the courtesy of greeting a stranger for lack of better nomenclature. In G hana, as in many parts of the world, greetings can be elaborate and are an essential part of daily life. To walk by someone without acknowledging him or her is an insult. Kwame Gyekye, a professor of philosophy at the U niversity of Ghana, in his book A frican Cultural Values explains that many African cultures place a high value on greeting, and believe that to refrain from greeting someone implies they are sub-human. It follows then, that when you pass a stranger you name them in order to greet them properly and acknowledge their humanity. On the street one often hears mal e foreigners called $\mathrm{K}$ wesi-bruni, a title which blends the common Akan name K wesi with the Oburoni label. ${ }^{14}$

It is also not uncommon for a stranger simply to be called "the bearded-one," "the short-one," "the fat-lady," or the "white-one" by passersby. Although at the U niversity of G hana the practice of greeting is much less rigid than it would be in a village, the practice does persist. And the indiscriminate use of "Oburoni" towards both white and black Americans often troubles student visitors who are unaware of its full meaning and in fact come from contexts where words like white and 
black, fat and thin are loaded terms. One African A merican describes it thus:

Someguy called someone Oburoni in our group and she got mad because sheis Caribbean and shewaslike"I'm not Oburoni," and hewas like, "Yes you are, all A mericans are Oburoni," and she was like, "W hat does that mean," and he said "white girl, white person," and she was like "I'm not white," and he was like "yeah you are, you are from A merica" and I said, "Look man, if you are black and in A merica, $\mathrm{N}$ o, you are not white." It's so true, you know. I take that seriously (BAM 1).

The nature of the term is hard for A mericans of any race to understand. But it seems equally difficult for $G$ hanaians to grasp the potentially insulting nature of this term for A frican Americans. First of all, it is common for light-skinned Ghanaians to be nicknamed "O buroni," and even a G hanaian who adapts western styles may be called an "Oburoni." One G hanaian student commented in this way:

It's only now on campus that people are beginning to comprehend that black people, A frican A mericas, find it offensive to be called Oburoni. B ut I don't think they mean it to be negative. It's not like I'm calling you Oburoni, foreigner because I want you to know that you are not one of us. It's just because peopl eare not that conscious of this slavery thing and what it means and how black A mericans feel about it. It's just I'm $G$ hanaian and you come from somew here, you come from across the $A$ tlantic in a plane and you're a guest, you're a foreigner, you're Oburoni. There are $G$ hanaians who are called Oburoni in their villages, anyonew ho is fair, or can't speak the language or some how is not very native (G F S1).

Despite this relatively gentle Ghanaian valence of the term, it becomes upsetting even to American whites- who are after all "correctIy" identified by the term. One expressed her discontent in an editorial in the $D$ aily $G$ raphic, a widely read national newspaper.

M y name is not Oburoni. Still, as I walk down the street I hear the call, "Oburoni!! E te sen?" and I know they are speaking to me. This one word, however, is a statement- you are different, in case you 
hadn't noticed yet. ... Sometimes I feel as if I am being told that I do not belong, as if I am being laughed at, as if I am being grouped with all other white people on earth- and such a generalization diminishes the individuality of which I am so proud ( $\mathrm{H}$ anley, $1998,14), 15$

A nother commented: "I don't think that it's necessarily negative, but it kind of bothers me when I walk by and people are just like, Oburoni, nothing else but Oburoni. I don't necessarily like it. It seems strange to be Oburoni and that's it" (WAF1). Despite this negative A merican reaction, none of the $G$ hanaian students interviewed considered Oburoni an insult. Indeed, a few suggested it might even be a compliment: "Oburoni is for whites. It's not an insult. It's just descriptive" (GFS2). An American student also reflected this sentiment and distinguished between the local meaning of the term and its $U$.S. reception:

I fel very accepted by $G$ hanaians on campus. It seems to me that they see meas a human being, as I see them as human beings. I made some friends, just plain friends. I don't think there is a negative stigma towards A mericans. A t first I took offense to the name Oburoni, because of the tone of voice But it's never used in a negative way. There are never insults that go along with it, usually compliments. "0, Oburoni, you look nicetoday." I don't takeit as a racial slur like we do in the States (WA M 1).

Clearly when diverse Americans are transplanted abroad, complex domestic race relations translate into complex perceptions overseas. Yet Ghanaian racial codes are wholly different, and indeed may not be appropriately described by categories such as "race." As we have seen, by virtue of having lighter skin and/or of being American, black and white A mericans are both often considered O buroni. This label, often received as a racial slur, not only negatively impacts Americans relations with Ghanaians, it can al so affect relations between black and white A mericans. Since many Ghanaians indiscriminately consider all Americans O buroni, in a sense the black and white A merican students are alone conscious of their difference. $\mathrm{H}$ ence the A mericans must reconcile their new collective identity with the separate racial identities they brought with them from overseas. The controversy surrounding the term "O buroni" demonstrates 
just how charged "race" is for Americans, and how difficult it is for A mericans and Ghanaians to comprehend fully non-national perspectives.

\section{Recommendations and Conclusion}

To this point, we have concentrated mainly on describing the complex situation-Ghanai an, African A merican, and European A merican- of the American student presence at the University of Ghana, Legon. Of course, as we have noted, no account is neutral, and our accounts have been inflected by the characteristics of the principal investigator (Landau), the co-writers (Landau and Moore), our many interlocutors, and by the broader cultural situations which have conditioned everyone's perspectives.

As we noted earlier, these observations at the U niversity of G hana may resonate with similar study abroad issues at other heritage locations around the world. We have observed that white A mericans, generally seeking a "cultural experience" (which happens to be the basis of the G hanaian tourist industry), often expressed satisfaction with their experience. However, African American expectations did not match their Legon experience, for reasons which may find parallels in other places. Yet we also recognize just how interwoven the relations and experiences of black and white A mericans and their Ghanaian peers are. We believe, in the final analysis, that this study abroad experience was enormously valuable and even transforming for its participants, despite and even as a result of the aforementioned challenges. Our goal then, is not simply to critique the Legon study abroad environment, nor to dissuade anyone from going, but rather to point out its positive and negative challenges, and from these develop possibilities for improving study abroad both there and worldwide.

In the title of this paper we used the word "reconciliation," and thus we'll now pause to discuss what, exactly, we see happening, and what we hope may happen, in study abroad contexts such as this around the world. In charged settings such as that found in Legon, reconciliation-a word mixed up with notions of settlement, resolution, adaptation, restoration, and even penance - might not ever be fully achieved. And yet it is important that reconciliation be continually sought after, by study abroad administrators, participants, and host nationals alike. Study abroad in Ghana and in many other places is clearly not an equal exchange. 
A merican students come to $\mathrm{G}$ hana more frequently than $\mathrm{G}$ hanaian students travel west, and economic differences are impossible to erase. And, while American youth expectations are shaped by stereotypes and, later, travel, Ghanaian expectations are more often shaped by inbound flows of media and people. Americans may be grappling with their global privilege and their deeply vexed race history, while Ghanaians confront limited resources and a relative lack of "race."

Of course, each participant in the network is affected in a different way. All parties are reconciling with unmet expectations. In the end it is the process of working towards some reconciliation that can powerfully affect student experiences. Because this essay is presented to a general professional audience, and not specifically to the Legon communities, we will refrain from offering specific suggestions. We would have confidence in the various parties to judge these steps themselves. Some of them cl early would include physical specifics, such as rethinking the housing situation, but more generally they would concern what goes on in people's heads. It is not clear, for example, the degree to which it is understood (on either side of the divide) that $\$ 2,000$-tuition for foreign students may allow lower rates or better infrastructure for national enrollees. Or, to choose a smaller issue, it is clear that greater attention to codes of Ghanaian student dress would help American students, who often seem sloppy and, because rich, therefore doubly disrespectful. Likewise, broader outreach to Ghanaians on the part of A merican program directors might improve $G$ hanaian understanding of A frican A merican reactions at Legon. All might benefit from sociolinguistic lessons on terms like "Oburoni." And, while direct enrollment programs are in our view the best approach to study abroad worldwide, these might be combined with pre-semester homestays to give American students more integrated, familial, city-wide (since Legon is near G hana's capital, Accra), and less "dormed-off" G hanaian links. Such stays would be further enhanced if arranged with Legon student families, who might encourage the visitors to engage in regular campus activities or clubs, dine at campus eating halls, or share A merican traditions with their hosts. Richer introductions for A mericans about the importance of things like formal greetings would al so be of use.

And yet, to address these specific questions, broad philosophical questions must be addressed. Should a host institution emphasize a total 
integration of its diverse student populations, or focus on a comfortable environment to insure future dollar flows? W hat are the objectives of the various U.S. programs, and the consequent responsibilities with respect to, for example, the marketing of "cultural experiences" and "heritage locations"? To what degree might social-education coordination among program officers and host institutions be advisable? H ow might one combat seemingly overwhelming global information flows in both directions? To what degree should the full international-education experience (Americans abroad, non-Americans here, and host nationals anywhere in contact with visiting student populations) be seen as a total system and not as a long roster of one-way adjustments? And what, finally, is the relationship between exile, stasis, and the typical American student's roundtrip ticket?

As noted in our introduction, the old models of study abroadwhich included homogeneous U.S. student populations, relative lack of charged heritage relations with receiving countries, lack of "racial" problematics between the visitors and hosts, general economic equality, and lack of conditioning global informatic frameworks- decreasingly work today. We want to underscore that though some cultural miscommunication is inevitable, it can belimited with insightful preparation and can, if respectfully assessed, result in even greater learning. Study abroad is, indeed, the ideal forum to demythologize stale stereotypes and work towards understanding. It is only in this reciprocal interrogation that a path towards reconciliation lies.

\section{N otes}

1 Some European locations such as I reland and to a lesser extent Italy have historical ly received heritage students. France's great popularity as a study abroad destination cannot be explained by the very small portion of French heritage in the United States, and England's high study abroad status likely stems from its position as the "default" prestige ethnicity for hybridized white Americans. The millions of Americans of Eastern European heritage (Polish Americans, for example) had extremely rare opportunities for heritage study abroad until roughly 1991.

2 W e note with appreciation $\mathrm{H}$ amil ton Beck's excel lent $\mathrm{F}$ rontiers article (1996) on W.E.B. DuBois as a study abroad student in Germany. 
3 Costs at the U niversity of G hana may be viewed at the U niversity of Ghana website: www.ug.edu.gh. The various A merican programs charge their U.S. students comprehensive fees of between five and six thousand dollars, generally including tuition, housing, registration, orientation, cultural activities, excursions, insurance and visa fees. In 1998, SU N Y Brockport estimated expenses at $\$ 6,200$, U CLA estimated $\$ 5,277, \mathrm{~N}$ orth Carolina State estimated $\$ 5,900$, and Council estimated $\$ 6,175$. Tufts' program operates differently. It charges normal Tufts tuition, using the extra money to support an exchange program for G hanaian graduate students, a cultural center in eastern G hana, and a sizable living allowance for the study abroad participants.

4 We express all financial information initially gathered in Ghanaian cedi in then-equival ent U.S. dollar terms, circa winter 2000. The fluctuating dollar/cedi rate, the variation in U niversity of $G$ hana fees, and the variation in U.S. study abroad program costs will render the financial information in this paper more ephemeral than the cultural observations.

5 A note on the difference between our use of "A merican" and "foreign." "Foreign" describes all non-Ghanaian students, all of whom are charged the standard non-national tuition. Most of Legon's nonGhanaians are other West African nationals, with a majority from Anglophone nations such as N igeria and Liberia. A sprinkling of nonAfrican (mostly graduate) students come from diverse locations such as N orway, J apan, Israel and England. Americans stand out among all foreign students for at least two reasons. First, they comprise $34 \%$ of the total number of international students on campus - the single largest national grouping and nearly $90 \%$ of the total Western population. And second, Americans are the only students with formal University-based sponsor programs, differentiating themselves from most other nonAfrican foreigners who enroll directly, typically to obtain an M.A. Most A mericans enroll as undergraduates for one or two semesters only. Although all foreign students are privileged in terms of lodging and amenities, Americans are particularly catered to because of both sheer number and program lobbying. Indeed, many on-site study abroad directors have faculty or staff positions at the $U$ niversity and can make special provisions. When the University goes on strike, some American programs hire faculty privately to hold classes for their students- not an 
option for other foreigners. We should note that the University's stated goal of $10 \%$ foreign enrollment implies a quadrupling of present nonG hanaian enrollment, to a total somewhere near 1,000 .

6 The broadest investigation of the general relationship between A frica and African A mericans (as opposed to Americans "in general") is found in Magubane (1987). Substantial scholarship has appeared on the cultural links specifically between the U.S. and South Africa (e.g., N ixon 1994), where the ties are much more of experience than of ancestry. The great African American writer Richard Wright's reflections specifically on G hana are found in his B lack Power (1954), though for many readers this book reveals more about Wright's own predilections than about either G hana or a "standard" African A merican view of Africa. W right's broadest reflections on race around the world are in his C ol or C urtain (1956). A very rich collection of African A merican travel writing, much of which concerns Africa, is found in Griffin and Fish (1998); this anthology can also serve as an excellent gateway to further reading on the African A merican experience abroad.

7 See Moore (1994).

8 For background on this longstanding political engagement, see Von Eschen (1997).

9 The Bush Canteen is an area designated for food sellers and merchants at the far corner of campus. Many students eat there during the day because the food is less expensive and more plentiful than the dining halls around campus.

10 In a previous issue of F rontiers, Susan Twombly (1995) offers a rich account of the dynamics of gender relationships between American women and host nationals during study abroad in Costa Rica, with important implications for study abroad locations in many places in the world.

11 Interestingly, $M$ aya A ngel ou reflected similar sentiments al most forty years ago (1985, p. 35).

12 For the broadest context of this discussion, see Paul Gilroy's landmark text The B lack A tlantic (1993).

13 This term is spelled in various ways in Ghana, most frequently 
"O buroni," but al so regularly "O bruni." Following D olphyne (1996), we will prefer the former spelling here. The term is typically capitalized.

14 The Akan people name their children according to the day of the week on which they were born. The name $\mathrm{K}$ wesi = born on Sunday.

15 It is remarkable the degree to which both black and white American student accounts of the "hailing" on the street reflect one of the most powerful analyses of racial naming, Frantz Fanon's "The Fact of Blackness" (1952).

\section{References}

Angelou, Maya. All God's Children Have Traveling Shoes. N ew York: $\mathrm{R}$ andom H ouse, 1986.

Baldwin, James. "A N egro A ssays the N egro Mood," in "Man's Relation to M an: Africa's Effect on the U.S N egro," C urrent (M ay, 1961): 6.

Beck, Hamilton. "W.E.B. DuBois as a Study Abroad Student in Germany." Frontiers: The Interdisciplinary J ournal of Study A broad. Fall, 1996: 45-63.

Dolphyne, Florence A bena. A Comprehensive Course In Twi (A sante). Accra, G hana: G hana U niversities Press, 1996.

Eze, Emmanuel Chukwudi. Race and the Enlightenment: A Reader. Cambridge, MA: Basil Blackwell, 1997.

Fanon, Frantz. "The Fact of Blackness." In his B lack Skin, W hite M asks. Trans. Charles Lam Markmann. N ew York: Grove Press, 1967, pp. 109-140. O riginally as "L'expérience vecue du noir," in his Peau noire, masques blancs. Paris: Seuil, 1952.

Gilroy, Paul. The Black A tlantic: M odernity and D ouble Consciousness. Cambridge, MA: H arvard University Press, 1993.

Griffin, Farah J., and Cheryl J. Fish, eds. A Stranger in the Village: Two Centuries of A frican-A merican Travel W riting. Boston: Beacon, 1998. Gruesser, J ohn Cullen. B lack on B lack: Twentieth-C entury A frican A merican W riting A bout A frica. Lexington: University of K entucky Press, 2000. Gyekye, Kwame. A frican Cultural Values. Accra, Ghana: Sankofa Publishing, 1996.

$\mathrm{H}$ anley, Elizabeth. "Experiences of an 'Oburoni' in Ghana," D aily G raphic (Accra, G hana) (N ovember 7, 1998): 14. 
Hickey, Dennis and Wylie, Kenneth. An Enchanting Darkness: The A merican Vision of A frica In the Twentieh Century. East Lansing: Michigan State University Press, 1993.

Magubane, Bernard Makhosezwe. The Ties that Bind: A frican-A merican Consciousness of A frica. Trenton, N J: A frica W orld Press, 1987.

M oore, David Chioni. "R outes: Alex H al ey's R oots and the R hetoric of Genealogy." Transition: A n International Review 64 (1994): 4-21.

$\mathrm{N}$ ixon, Rob. $\mathrm{H}$ omelands, $\mathrm{H}$ arlem, and $\mathrm{H}$ ollywood: South A frican Cultureand the W orld B eyond. N ew York: Routledge, 1994.

Twombly, Susan B. "Priopos and Friendships: Gender and Culture Clash in Study Abroad." Frontiers: The Interdisciplinary J ournal of Study A broad. Fall, 1995: 1-27.

University Planning U nit, U niversity of G hana at Legon. B asic Statistics, 1998.

Von Eschen, Penny M. Race A gainst Empire: Black A mericans and A nticol onialism, 1937-1957. Ithaca: Cornell U niversity Press. 1997. Wright, Richard. Black Power: A R ecord of Reactions in a Land of Pathos. N ew York: H arper \& Bros, 1954.

Wright, Richard. The $C$ ol or $C$ urtain: $A$ Report on the $B$ andung $C$ onference. Cleveland and N ew York: World Publishing, 1956.

W ebsite resources. W ebsites for the U S.S.-sponsored Legon study abroad programs discussed here may be found at these U niform R esource Locators. We caution that URL addresses are often subject to change, and suggest interested parties go to the home pages of the respective institutions, or to a broader links site such as www.studyabroad.com.

Council: $\quad$ www.ciee.org/study/africa/ghana/legon/index.htm NC State: www.ncsu.edu/chass/mds/studyab.html Tufts: $\quad$ www.ase.tufts.edu/studyabroad/tpa/ghana.html Brockport: www.studyabroad.com/suny/brockport Missouri web.missouri.edu/ icweb/studyabroad/programs /legon.htm

California: www.uoeap.ucsb.edu/eap/country/ghana/gh.htm

The U niversity of Ghana website is www.ug.edu.gh. 